\title{
PREDICTION OF TORQUE PULSATIONS IN BRUSHLESS PERMANENT-MAGNET MOTORS USING IMPROVED ANALYTICAL TECHNIQUE
}

\begin{abstract}
Arash Kiyoumarsi
Torque pulsations have prominent effects on the performance of brushless permanent- magnet (PM) machines. There are different sources of torque ripples in PM motors. These torque pulsations depend on the shape of the flux density distribution in the airgap region. For predicting the open-circuit airgap field distribution in brushless PM motors, a two dimensional (2-D) analytical method, in which the direction of magnetization, either radial or parallel and the effect of the stator slot-openings are taken into account, is used. The method uses an improved 2-D permeance model. In order to evaluate the accuracy of this method, a 2-D time-stepping FEM coupled with the two motion equations is used. A 3-phase, 36-slot, 4-pole, 5 HP, brushless PM motor is modeled by two methods. In this analysis both, the radial and parallel magnetization of the brushless motor are considered. The results obtained by the analytical method are compared with those obtained by FE analysis that shows the valuable accuracy of the analytical method for performance calculations in design and optimization processes.

K e y w o r d s: brushless permanent-magnet motors, stator slots, torque ripples, time stepping finite element method
\end{abstract}

\section{INTRODUCTION}

Brushless permanent-magnet (PM) motors can be divided into the PM synchronous AC motor (PMSM) and brushless DC motor (PMBDCM). The former has sinusoidal airgap flux and back EMF, thus has to be supplied with sinusoidal current to produce constant torque. The PMBDCM has the trapezoidal back EMF in which the rectangular current waveform in armature winding is required to obtain the low ripple torque $[1,2]$. Generally, the magnets with parallel magnetization are used in the PMSM while the magnets with radial magnetization are suitable for the BDCM. The permanent magnet mounting in different motors with different magnetization and direction of magnetization are compared in [3]. Torque ripple minimization in PM motors is conventionally obtained by either good motor design or appropriate control strategies. In design optimization programs, an accurate and detailed analysis of the torque and back EMF of the machine should be performed. The analysis of both mentioned criteria have almost been strongly studied via explicit expressions for the airgap flux density distribution.

The total resultant instantaneous torque of a brushless permanent magnet motor has two components, a constant or useful average torque and a pulsating torque which causes torque pulsations $[4,5]$. There are three sources of torque pulsations. The first is field harmonic torque due to non-ideal distribution of flux density in the airgap, ie, non-sinusoidal in the PMSM or non-trapezoidal in the BDCM. The second is due to the cogging torque or detent torque caused by the slotted structure of the armature and the rotor permanent magnet flux. The third is reluctance torque, produced due to unequal permeance of the d- and q-axis. This torque is produced by the selfinductance variations of phase windings when the mag- netic circuits of direct- and quadrature-axis are unbalanced [5]. The mutual or commutation or instantaneous electromagnetic torque includes main torque (average torque) and the field harmonic electromagnetic torque. The mutual torque is produced by the interaction between PM field and the armature field due to phase currents. Electromagnetic torque can be calculated with either the phase currents and back EMF of phases or stator MMF and the rotor PM flux [6].

Cogging torque results from the interaction of the airgap permeance function harmonics-because of stator saliency developed by stator slots and the teeth-and the PM mmf harmonics produced in the airgap. Its effect is to align/unalign the rotor in a number of stable/unstable positions even in unexcited machine and has a pulsating waveform with zero average or effective torque [7-10]. The interaction of the magnet $\mathrm{mmf}$ with space harmonics of the stator winding and time harmonics in the stator current waveforms produces torque components that are electromagnetic (ripple torque). Indeed, cogging torque is a consequence of non-current condition [1]. The summation of cogging torque and ripple torque is usually named as torque pulsations.

At a glimpse, in this paper, in section 2 the modeling of stator slots for the magnetic field problem is briefly considered. There, in that section, there is an improvement in field density distribution calculation that is used latter, in sections 4 and 5 for torque evaluation. Then, in section 3, calculation of open-circuit flux density distribution via analytical methods is briefly discussed. In this section, the illustrations that brought in section 2 are also used for prediction of magnetic flux density much more precise than the previous analytical method. At a glance, sections 4 and 5 review the analytical method in

\footnotetext{
* Department of Electrical Engineering, Faculty of Engineering, University of Isfahan, Isfahan, Iran. PO Box 81746-73441, kiyoumarsi@eng.ui.ac.ir
} 


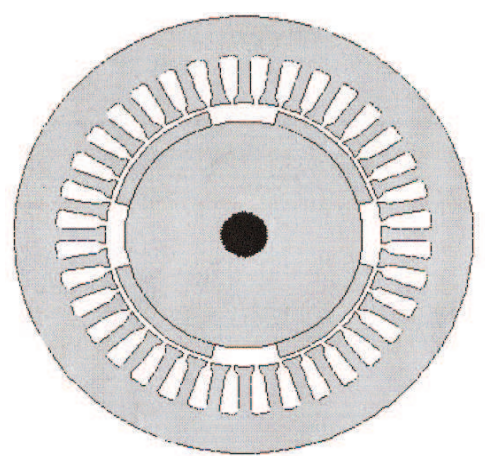

Fig. 1. Cross section of the machine

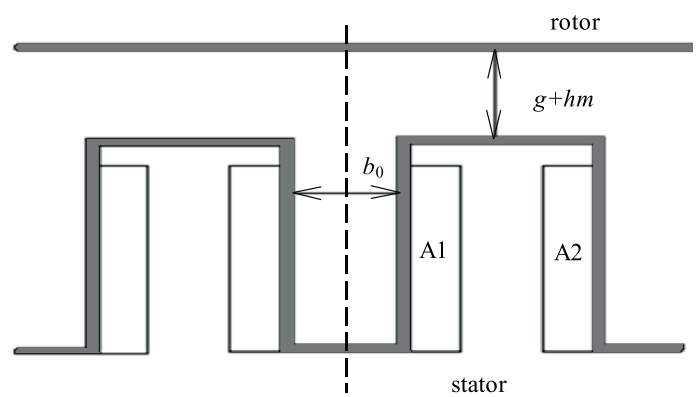

Fig. 2. The actual slot construction considered in the new method for analytical torque calculations

order to predict the cogging and interaction torques in the surface-mounted permanent-magnet machines. Section 6 deals with the process of torque prediction and calculation by means of two different methods, ie Local Virtual Work and Maxwell Stress Tensor Method that are usually used meanwhile torque calculations in rotating electrical machines. Moreover, the simulation results, in order to reveal the effectiveness of the proposed improved method, are completely added to the paper in section 7 . In a comprehensive illustration, finally, there is a conclusion in section 8 . The paper contains two appendices. At first, the parameter values of the prototype brushless PM motor are included in Appendix 1. Secondly, a list of the symbols, as the second appendix, introduces the symbols used in the paper.

\section{EFFECT OF STATOR SLOT OPENINGS}

An effective method for modelling the influence of the stator slots on the magnetic field distribution in PMBDCM with surface-mounted magnets is presented in [11, 12]. The proposed 2-D function assumes infinitely deep rectilinear stator slots. This relative permeance function has a Fourier series of the form

$$
\tilde{\lambda}(r, \alpha)=\sum_{n=0}^{\infty} \tilde{\Lambda}_{n}(r) \cos \left(n Q_{s}\left(\alpha+\alpha_{s a}\right)\right)
$$

Figure 1 shows the cross section of the machine that is used in this study, which was previously designed by the author. This initial relative permeance function has been used to study the more realistic stator slot, as shown in Fig. 2. Each stator slot, can be regarded as the initial model plus two new virtual stator regions, ie A1 and A2 as shown in Fig. 1, with A0 as the original tooth. Hence the relative permeance of the real stator slots can be calculated as follows

$$
\tilde{\lambda}(r, \alpha)=\tilde{\lambda}_{0}(r, \alpha)-\tilde{\lambda}_{1}(r, \alpha)-\tilde{\lambda}_{2}(r, \alpha)
$$

The reference for the $\alpha$ (in $\left.\tilde{\lambda}_{0}(r, \alpha)\right)$ ie $\alpha=0$, is the axis of the mmf of the phase A winding.

\section{OPEN-CIRCUIT FIELD DISTRIBUTION}

A 2-D analytical model for calculating the field distribution in the airgap region of surface-mounted PM brushless motors $[11,12,13,15]$ and buried permanent magnet brushless motors [15] is developed. Both the radiallymagnetized and in-parallel-magnetized are considered. The calculation of open-circuit field distribution has been completely described as follows

$$
B_{\text {open-circuit }}(r, \alpha, t)=B_{\text {magnet }}(r, \alpha, t) \tilde{\lambda}(r, \alpha)
$$

In Fig. 3 and Fig. 4, the flux density distribution results of different methods are successfully compared that are obtained for the machine considered in Fig. 1.

\section{PROPOSED FRAMEWORK MODEL}

The cogging torque is calculated by means of a method used in [16-19] along with a modified new method. In the previous method, the flux density under each stator slot is assumed to be zero while the entire flux of the slot pitch will pass through the stator tooth. In the new method, the effect of the finite stator slot is considered directly in calculations. Both the results of previous method and the results of new method are compared with those obtained by FE analysis. The cogging torque can be expressed by the following equations [16-19]

$$
\begin{gathered}
T_{\text {cogg }}=(P / 2) \frac{\partial W_{c o}}{\partial \theta_{r}} \\
W_{C O}=\iint \frac{B^{2}}{2 \mu_{0}} g r d l d \theta
\end{gathered}
$$

$B$ has been successfully derived for both methods as defined below

$$
B_{\text {prev }}=\left\{\begin{array}{l}
0 \quad 0<\theta<W_{s} / 2 \\
\left(1+\frac{W_{S}}{W_{t}}\right) B_{\text {magnet }} W_{s} / 2<\theta<W_{s} / 2+W_{t}
\end{array}\right.
$$

and

$$
B_{\text {new }}=B_{\text {open-circuit }}(r, \alpha, t)
$$

The analysis, here in this paper, is performed for the surface-mounted PM machines. 


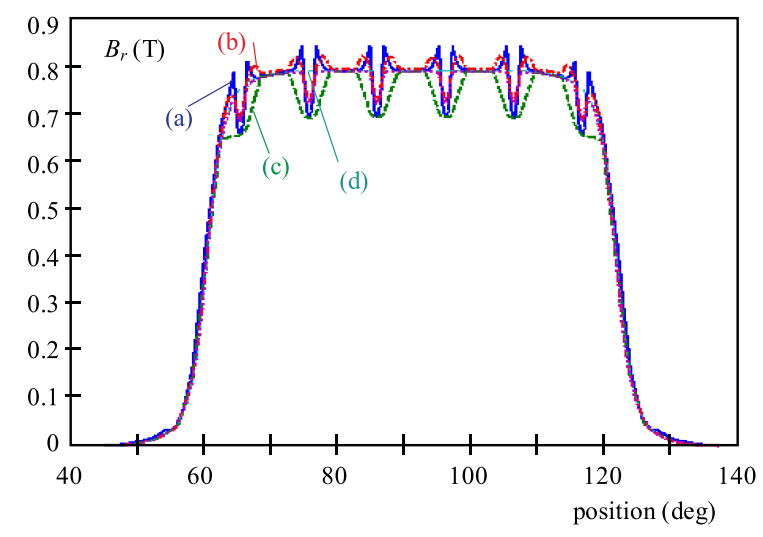

Fig. 3. Flux density distribution under one magnetic pole produced by permanent-magnet, radial magnetization (a) - $B_{\text {sum }}$ (FEM), (b) $-B_{o c n},(\mathrm{c})-B_{r}(\mathrm{FEM}),(\mathrm{d})-B_{o c b}$

\section{THE COMMUTATION TORQUE ANALYSIS}

The total instantaneous electromagnetic torque of the machine can be calculated from the Lorentz force formula as in $[16]$

$$
T_{\text {comm }}=p r^{2} \iint B(r, \theta) J(\theta, l) d l d \theta
$$

or via the following equation $[2,3,5]$

$T_{c o m m}=\frac{1}{\omega_{m}}\left[e_{f A}(t) i_{f A}(t)+e_{f B}(t) i_{f B}(t)+e_{f C}(t) i_{f C}(t)\right]$

To predict the electromagnetic torque, the first method is used and the integral of (5) is evaluated for both the buried-magnet and the surface-mounted PM [16]-[19] (radially-magnetized and in-parallel-magnetized). The total motor torque can be obtained by adding these torques, ie

$$
T_{\text {res }}(t)=T_{\text {cogg }}(t)+T_{\text {comm }}(t)
$$

\section{ANALYSIS OF BRUSHLESS PM MOTOR WITH MAGNETIC NON-LINEARITY}

The analysis is based on the time-stepping electromagnetic 2-D finite element formulation with rotor motion. In voltage-fed motor, the three-phase circuit and the governing 2-D electromagnetic field equations are coupled to each other. A time-stepping coupled finite element method is used to solve the transient electromagnetic field problem. The airgap of the machine is divided to two layers. This two-layer airgap region is used and constraint equations are also written between the nodes of these two layers. For analysis of the transient period due to the rotor motion, the instantaneous torque at each instant is calculated by both the local virtual work (LVW) method and Maxwell stress tensor (MST) method, ie the torque acting on the rotor at each time step is calculated by the line integral of the Maxwell stress tensor. The above illustrations are followed by a flowchart which is shown in Fig. 5. The type of each element, both in magnetic

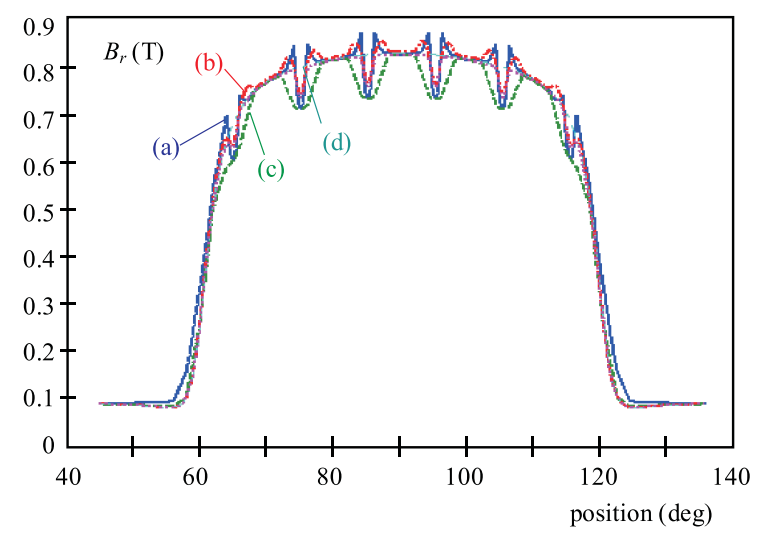

Fig. 4. Flux density distribution under one magnetic pole produced by permanent-magnet, parallel magnetization (a) $-B_{\text {sum }}$ (FEM), (b) $-B_{o c n},(\mathrm{c})-B_{r}$ (FEM), (d) $-B_{o c b}$

model and electrical circuit, ie the degrees of freedom of magnetic and electrical nodes, number of nodes and the shape functions have also been cautiously selected. In the current-fed machine, the current of each phase is directly injected to the corresponding coils in a two-layer winding by using a predefined current surface density waveform. The shape of the torque waveform has a dc component and a pulsating term in which a fundamental frequency related to 6 pulses per a 360 electrical degrees rotation of the rotor exists [20-22].

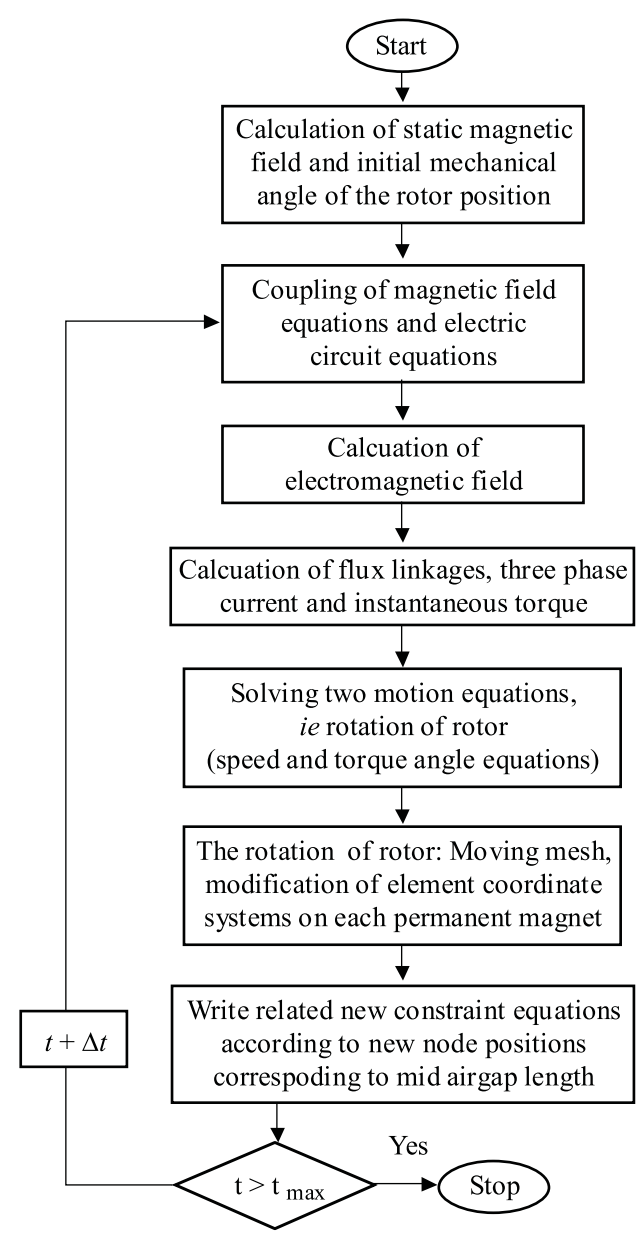

Fig. 5. The actual slot construction considered in the new method for analytical torque calculations 


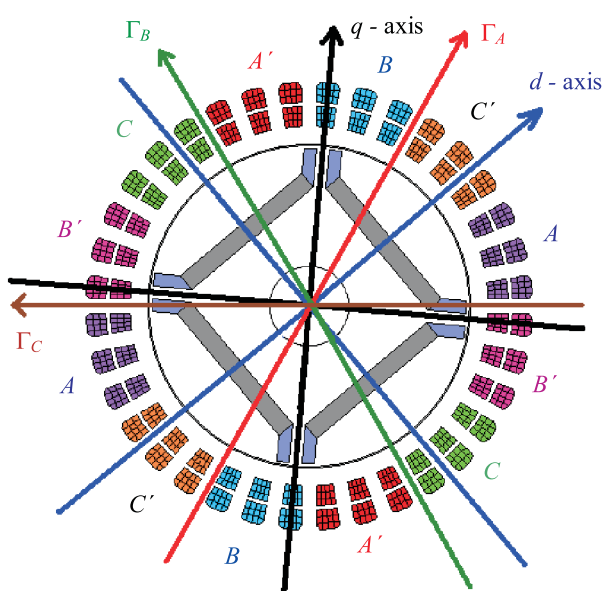

Fig. 6. D- and Q-axis and their relative electrical degrees with respect to MMF of phase $\mathrm{A}$

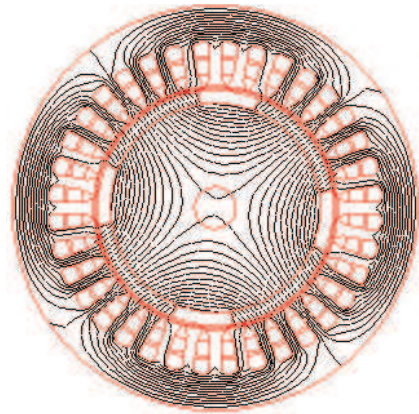

(a)

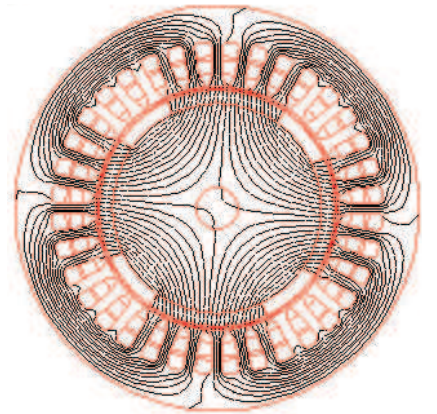

(b)
Fig. 8. Time stepping 2-D FEM results for the flux lines at no-load condition, parallel magnetization, SPMSM

In order to compare the analytical results and FEAbased results, the tangential and radial components of mid-airgap flux density distributions have been calculated via the FEM on the excited and unexcited stator current machine. In 2-D problems, tangential (the average airgap shear stress) and radial (the circumferential traction) stresses may be expressed

$$
\tau_{r}=\frac{1}{2} \nu\left(B_{r}^{2}-B_{\theta}^{2}\right), \quad \tau_{\theta}=\frac{1}{2} \nu B_{r} B_{\theta}
$$

where $\tau_{r}$ and $\tau_{\theta}$ are defined as Maxwell's stress tensors. The total instantaneous torque can then be given by

$$
T_{e}=\nu_{0} L_{R} r_{e q} \oint_{\Gamma} B_{r} B_{\theta} d \Gamma
$$

In (13), $L_{R}$ is the effective length of the rotor and $r_{e q}$ is the mid-airgap radius of the machine. According to [2022 ], integration is accomplished over the circular cylinder that surrounds the rotor by a closed surface and is located at the mid-airgap region, $\Gamma$ is the path(circle) around the rotor, ie the cross-section of the cylinder and a plane perpendicular to the rotor. (a)

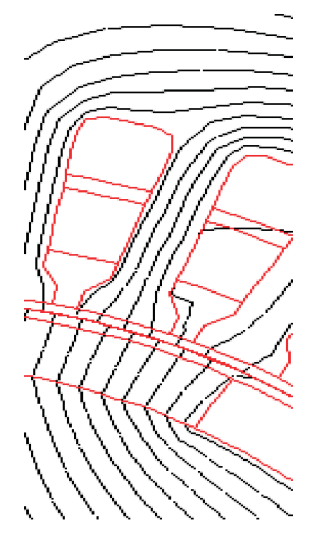

(b)

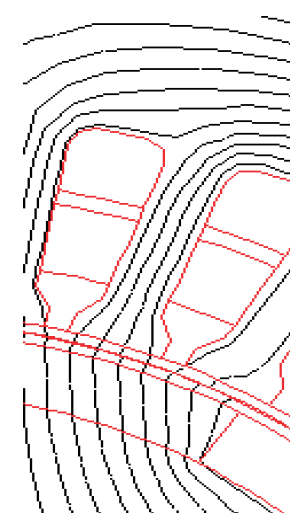

Fig. 7. Equipotential lines: Instantaneous flux distribution due to magnets acting alone (open-circuit condition) at time $\mathrm{t}=0$, (a) radial magnetization, (b) - parallel magnetization

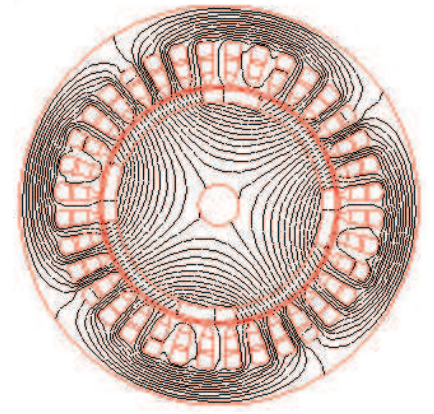

(a)

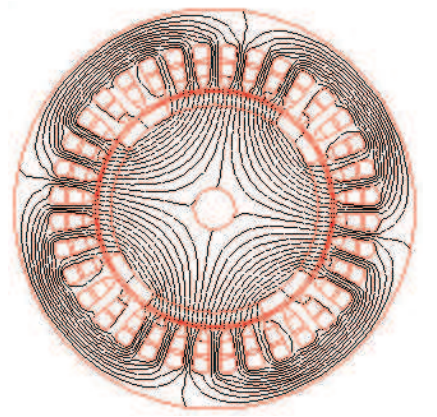

(b)
Fig. 9. Time stepping 2-D FEM results for the flux lines at half load condition, parallel magnetization, SPMSM, sinusoidal fed currents

Local virtual work method, however, is a local method for predictiong the torque and is described on every element as follows

$$
T=\frac{E(\theta+\delta \theta)-E(\theta)}{\delta \theta}
$$

Howe and Zhu [23] studied the influence of mesh discretisation on the cogging torque predictions. Both the energy method and Maxwell Stress integration are considered and they suggest that it is better to integrate torque density stresses through the central layer of airgap elements and also employ a fine mesh discretisation.

A cross section of a $5 \mathrm{HP}, 1500 \mathrm{rpm}$, 4-pole brushless PM machine and its stator fully-pitched, double-layer, three-phase winding [24-27] with which the study is carried out, in this paper; is provided in Fig. 6. The results of FEM are followed in Fig. 7 to Fig. 12.

The performance of the electrical drive is coupled to the FE model indirectly, ie the ideal waveforms of the stator currents are fed to the FE model. The electrical circuit, in which end effects are also encountered, is coupled to the FE model. It relates voltage sources to nodes of slots. Rotor and stator are ferromagnetic materials (M-19, M-36) and the machine excitation is provided by 

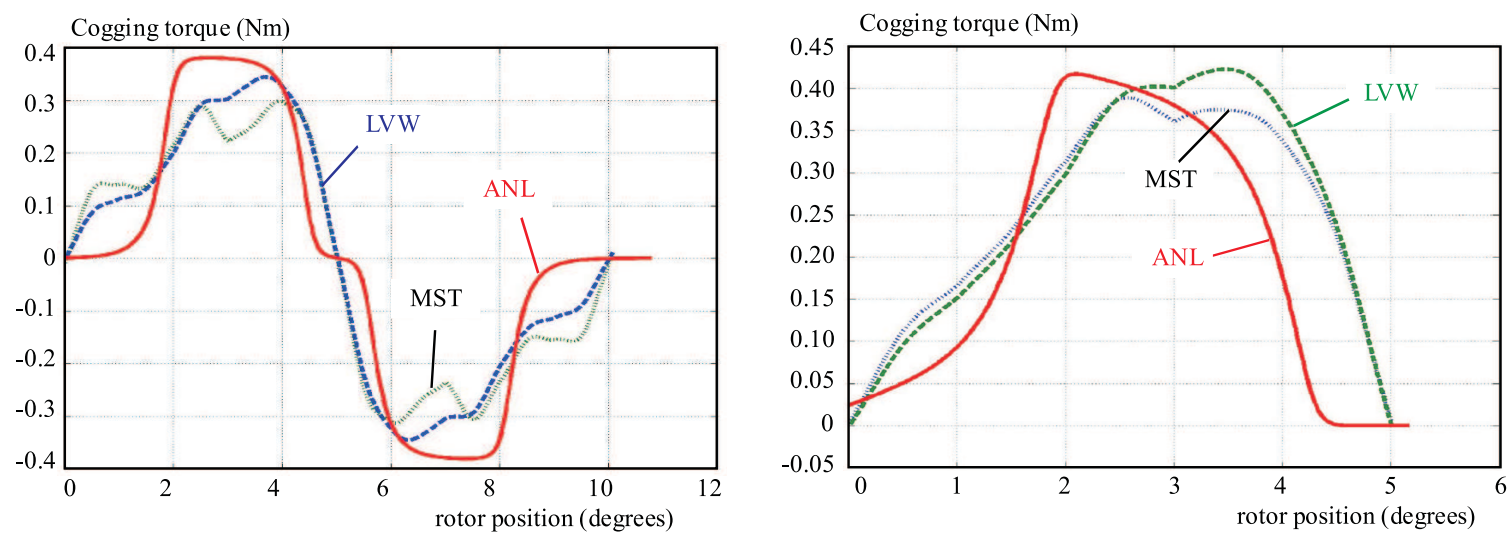

Fig. 10. Cogging torque analysis Analytical results (ANL) and Numerical results (LVWM \& MSTM) (a) - radial magnetization, (b) parallel magnetization
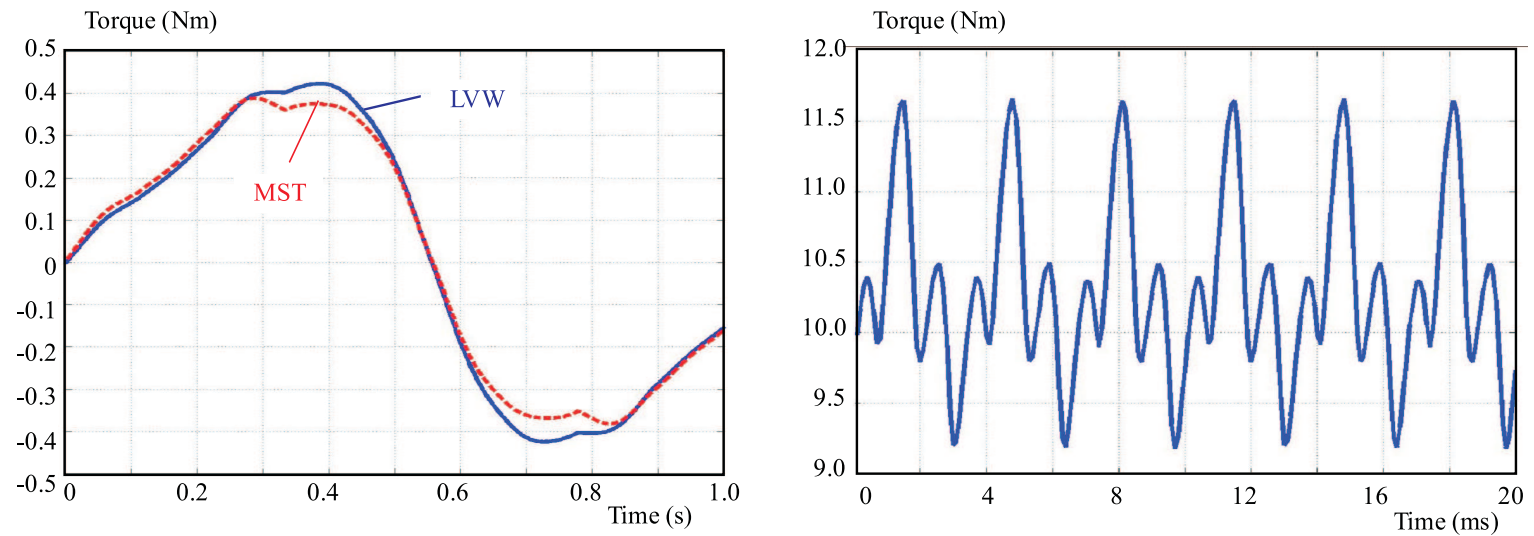

Fig. 11. The FEM results: Parallel Magnetization; (a) - cogging torque, (b) - instantaneous torque

Nd-Fe-B (N33) permanent magnets [25-27]. The radiallymagnetized motor is supplied by square-wave current waveforms and in-parallel-magnetized motor is supplied by sine-wave current waveform.

\section{SIMULATION RESULTS}

In this section, the results of simulations of both radial and parallel magnetizations are involved. Figs. 7-a and 7-b show the sliding surface, by which the rotation of the rotor is modeled, at the middle of the airgap of the machine for these two different magnetization directions. Figs. 8 and 9 show the rotor situation at different times for a period of $5 \mathrm{~ms}$ that is the result of the time stepping 2-D FEM for the parallel magnetization motor, at no-load and load conditions respectively. The revolution of the rotor and resultant rotating magnetic field, which includes the rotor and stator magnetic fields, are obviously evident in these figures.

Based on the $d$ - and $q$-axis for this four-pole synchronous machine, appropriate initial conditions for rotor angle and phase current related to prescribed load conditions, are carefully selected for steady-state operation of the motor. The whole schematic of the axes are shown in Fig. 6. Figure 10 shows cogging torque analysis results obtained by the analytical results (ANL) and numerical results, ie local virtual work method and Maxwell stress tensor (LVWM \& MSTM), for both the in-parallel and radial magnetizations. In Figs. 11 and 12, the time-stepping FEM results for parallel magnetization and radial magnetization are respectively included. In these two figures, the first cure shows the cogging torque, which is the produced torque when there are no injected currents into the stator windings. The second curve contains the overall instantaneous electromagnetic torque waveform, with which the whole torque pulsations, ie cogging torque and torque ripples can be jugged.

For this designed 4-pole brushless PM motor, which is fed by the stator phase currents that have a fundamental component with the frequency of $50 \mathrm{~Hz}$, the torque waveform has an average value and a pulsating component that repeats six times per one cycle of the current or flux variations. In this 4-pole machine, therefore, one revolution of the rotor means 360 mechanical degrees and 720 electrical degrees, $i e$, flux waveform repeats twice in one complete rotation of the rotor. One pole-pitch of the machine may be interpreted as either 180 electrical degrees or 90 mechanical degrees (Figs. 3 and 4), ie one half of the period of the flux density distribution. On the other hand, one slot-pitch of the machine is equal to either 20 electrical degrees or 10 mechanical degrees. This shows that the cogging torque waveform completely repeats in a 10-degree period in mechanical degrees (Fig. 10.a and $10 . \mathrm{b})$. In this 4-pole machine, time variations of $20 \mathrm{~ms}$ torque waveform means 360 electrical degrees variations (Figs. 11 and 12). 


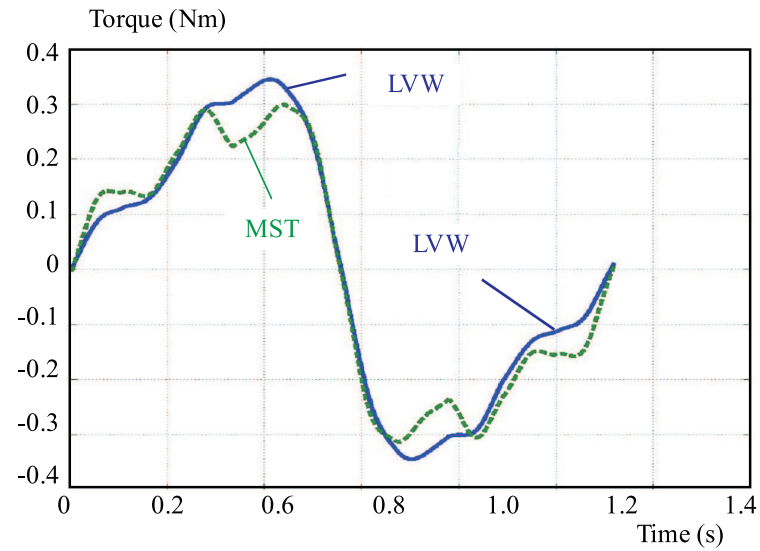

Fig. 12. The FEM results: Radial Magnetization;

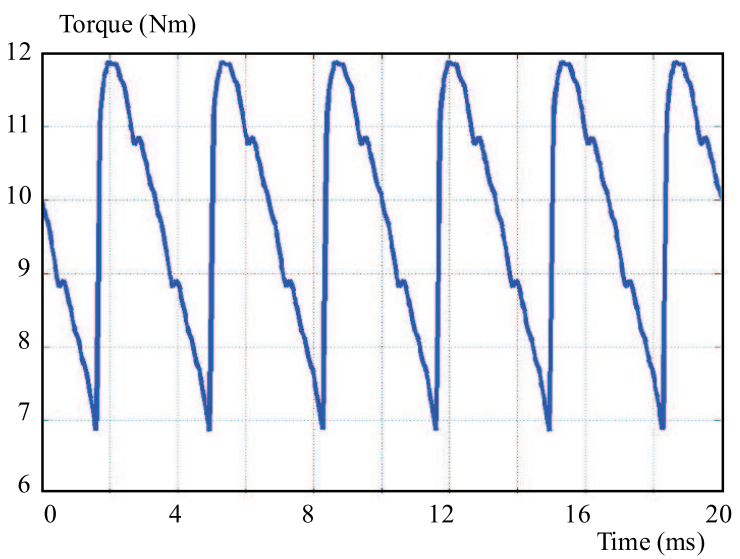

(a) - cogging torque, (b) - instantaneous torque

\section{CONCLUSION}

In this paper, both the cogging and interaction electromagnetic torques of a prototype machine, ie brushless permanent-magnet motor, are predicted by using a new improved analytical method. The analytical results are compared with the time-stepping 2D FEM results. Both the local virtual work method and Maxwell stress tensor method are used to evaluate instantaneous electromagnetic torque of motor by time-stepping 2-D FEM. Using a software, a FEM-analysis program, which performs corresponding simultaneous field and motion equations, has been provided to solve the integral-solutions between field and circuit equations. For coupling the electrical circuit to the magnetic circuit and the torque-speed mechanical equations, the time variations of the problem, ie the rotation of the rotor and time variations of the stator currents have been taken into account. The good agreements between the FEM results and the new analytical results validate the new improved analytical method, which can be used much simpler than the FEM, as a fast computational tool for design optimization of brushless PM motors.

\section{Acknowledgement}

Special thanks are dedicated to the center of research and technology, at the University of Isfahan for their full support. The author participated in the Advanced Finite Element and Electromagnetic courses when he was a Post-Doctoral research fellow of the Alexander von Humboldt Foundation under the supervision of Professor Rolf Hanitsch, at the Institute of Electrical Machines and Renewable Energies, at Technical University of Berlin (TUBerlin). This participation improved the knowledge of the first author about the Finite Element Method and its applications in Electromagnetics. Special thanks also go to the staff of the Alexander von Humboldt Foundation, for their full support to the author. Valuable comments from the anonymous reviewers indeed helped to significantly improve and enhance the contents of this research. I would really appreciate their comprehensive attentions and vital considerations.

\section{APPENDIX I}

Parameters of the brushless PM motor prototype:

Stator

$\begin{array}{ll}r_{s o}= & 97.1 \mathrm{~mm} \text { - outer radius } \\ r_{s i}= & 58.5 \mathrm{~mm} \text { - inner radius } \\ l_{s}= & 76.0 \mathrm{~mm} \text { - length } \\ h_{y}= & 17.4 \mathrm{~mm} \text { - yoke depth } \\ h_{t}= & 17.2 \mathrm{~mm} \text { - tooth depth } \\ h_{t t}= & 2.0 \mathrm{~mm} \text { - tooth top thickness } \\ & 36 \mathrm{number} \text { of slots } \\ b_{0}= & 5.1 \mathrm{~mm} \text { - slot opening } \\ N_{s}= & 96-\text { stator turns per phase }\end{array}$

lamination: steel M36, fully processed-29 gage

winding: double-layer, fully-pitched

Rotor

$r_{\text {ro }}=\quad 56.5 \mathrm{~mm}$ - outer radius

$r_{r i}=\quad 50.2 \mathrm{~mm}$ - inner radius

$l_{s}=\quad 76.0 \mathrm{~mm}$ - length

$2 p=4$ - number of poles

$B_{\text {res }}=1.1 \mathrm{~T}$ - remanence

$\mu_{r}=\quad 1.05$ - relative recoil premeability

$h_{m}=6.3 \mathrm{~mm}$ - magnet height

$2 \alpha_{m}=\quad 60 \mathrm{deg}$ - magnet arc angle

lamination: Steel M19, fully processed-29 gage

magnet: Nd-Fe-B, N33

\section{APPENDIX II}

List of Symbols:

$B_{\text {magnet }}$ flux density due to magnet at stator inside surface

$B_{\text {open-circuit }}$ Open-circuit flux density distribution

$\lambda_{s} \quad$ relative permeance function

$Q_{s} \quad$ slot number

$\Lambda_{\text {ref }} \quad$ reference permeance

$b_{0} \quad$ stator slot-opening

$\alpha \quad$ the angular position variable

$\alpha_{s a} \quad$ angular displacement between the stator slot axis and the axis of the coils of phase A

$B_{\text {sum }} \quad$ absolute resultant open-circuit flux density obtained by FEM

$B_{\text {ocn }} \quad$ open-circuit flux density - new method

$B_{o c b} \quad$ open-circuit flux density - Boules' method 
$B_{r}$ open-circuit flux density, only assuming radial component of flux density, obtained by FE analysis

a stator inside radius

$c_{1}$ magnet inside radius

$c_{2}$ rotor outside radius

$R$ radial magnetization

$P$ parallel magnetization

$B_{\text {res }}$ residual flux density of magnet

$\alpha_{m}$ pole arc angle

$g^{\prime \prime}$ equivalent magnetic airgap

\section{REFERENCES}

[1] HENDERShOT, J. R. JR.-MILLER, T. J. E. : Design of Brushless Permanent-Magnet Motors, Magna Physics Publishing and Clarendon Press, Oxford, 1994.

[2] JOHnS, T. M.-SOONG, W. L.: Pulsating torque minimization techniques for permanent magnet $\mathrm{AC}$ motor drives - a review, IEEE Transactions on Industrial Electronics 43 No. 2 (1996), 321-330.

[3] CAI, W.-FUlton, D.-REICHERT, K.: Design of permanent magnet motors with low torque ripples: a review, ICEM 2000, ESPO, Finland, (2000), 1384-1388.

[4] JAHNS, T. M.: Torque production in permanent-magnet synchronous motor drives with rectangular current excitation, IEEE Transactions on Industry Applications IA-20 No. 4 (July-August1984), 803-813.

[5] GIERAS, J. F.-MARLER, M. E.: Analytical prediction of torque ripple in permanent magnet brushless motors, ICEM 2002 (August 2002), 25-28.

[6] FAVRe, E.-CARDoletti, L.-JUfER, M. : Permanentmagnet synchronous motors: A comprehensive approach to cogging torque suppression, IEEE Transactions on Industry Applications 29 No. 6 (November/December 1993), 1141-1149.

[7] ZHU, Z. Q.-HOWE, D. : Analytical prediction of the cogging torque in radial-field permanent magnet brushless motors, IEEE Transactions on Magnetics 28 No. 2 (March 1992), 1371-1374.

[8] HANSELMAN, D. C.: Effect of skew, pole count and slot count on brushless motor radial force, cogging torque and back EMF, IEE proceedings -Electric Power Applications 144 No. 5 (September 1997).

[9] ENOKIZONO, M.-TSUZAKI, T.: Magnetic field analysis of anisotropic permanent magnets, Non-linear Electromagnetic Systems, V. Kose and J. Sievert, IOS press, (1998).

[10] MOSEBACH, H.: Two-dimensional analytical torque calculation of permanent magnet excited actuators and machines with large airgap, Non-linear Electromagnetic Systems, V. Kose and J. Sievert, IOS press (1998).

[11] ZHU, Z. Q.-HOWE, D.: Influence of design parameters on cogging torque in permanent-magnet machines, IEEE Transactions on Energy Conversion 15 No. 4 (December 2000), 407-412.

[12] ZHU, Z. Q.-HOWE, D. : Instantaneous magnetic field distribution in brushless permanent magnet DC motors, part II: Armature-reaction field, IEEE Transactions on Magnetics 29 No. 1 (January 1993), 136-142.

[13] BOULES, N. : Two-dimensional field analysis of cylindrical machines with permanent magnet excitation, IEEE Transactions on Industry Applications IA-20 (September/October 1984), $1267-1277$.
[14] BOULES, N.: Prediction of no-load flux density distribution in permanent magnet machines, IEEE Transactions on Industry Applications IA-21 (1985), 633-643.

[15] BOULES, N. : Field analysis of PM synchronous machines with buried magnet rotor, General Motors Research Laboratories, Warren, MI 48090-9055, (1986), 1063-1066.

[16] REE, J. D.-BOUlES, N.: Torque production in permanent-magnet synchronous motors, IEEE Transactions on Industry Applications 25 No. 1 (1989), 107-112.

[17] PARK, S. J.- et al : A new approach for minimum-torque-ripple maximum-efficiency control of BLDC motor, IEEE Transactions on Industry Applications 47 No. 1 (February 1993), 109-114.

[18] CHAPMAN, P. L.-SUDHOFF, S. D.-WHiTCOMB, C. A. : Optimal current control strategies for surface-mounted permanent-magnet synchronous machine drives, IEEE (2002).

[19] DAI, M.-KEYHANI, A.-SEBASTIAN, T. : Optimal current control strategies for surface-mounted permanent-magnet synchronous machine drives, IEEE (2002).

[20] BOLDEA, I-NASAR, S.: The Induction Machine Handbook, CRC Press, (2002).

[21] GIERAS, J. F.-PIECH, Z. J.: Linear Synchronous Motors, Transportation and Automation Systems, CRC Press, LLC, (2000).

[22] YEADON, W. H.-YEADON, A. W. : Handbook of small electrical motors, McGraw-Hill companies, (2001).

[23] ZHU, Z. Q.-HOWE, D. : Analytical prediction of the cogging torque in radial -field permanent magnet brushless motors, IEEE Transactions on Magnetics 28 No. 2 (March 1992), 1371-1374.

[24] SLEMON, G. R.-LIU, X. : Core losses in permanent magnet motors, IEEE Transactions on Magnetics 26 No. 5 (September 1990), 1653-1655.

[25] KIOUMARSI, A.-MOALLEM, M.-FAHIMI, B. : Mitigation of torque ripple in interior permanent magnet motors via optimal shape design, IEEE Transactions on Magnetics, Regular Transactions (November 2006), 3706-3711.

[26] KIYOUMARSI, A.-HASSANZADEH, M. R.-MOALLEM, M. : A new analytical method on field calculation for interior permanent-magnet synchronous motors, International Journal of Scientia Iranica, Sharif University of Technology 13 No. 14 (October 2006), 364-372, Iran.

27] MOALlEM, M.-KIYOUMARSI, A.-HASSANZADEH, M. R. : A novel technique on the anlalytical calculation of open-circuit flux density distribution in brushless permanent-magnet motor, International Journal of Engineering (April 2004), 51-58, Iran.

Received 29 November 2008

Arash Kiyoumarsi was born in Shahr-e-Kord, Iran, 1972. He received his BSc (with honors) from Petruliom University of Technology (PUT), Iran, in electronics engineering in 1995 and MSc from Isfahan University of Technology (IUT), Iran, in electrical power engineering in 1998. He received PhD degree from the same university in electrical power engineering in 2004. In March 2005, he joined to the University of Isfahan, Faculty of Engineering, Department of Electrical Engineering as an assistant professor. He was a Post-doc. research fellow of the Alexander von Humboldt foundation at the Institute of Electrical Machines, Technical University of Berlin from February to October 2006 and July to August 2007. His research interests have included application of finite element analysis in electromagnetics, interior permanent-magnet synchronous motor drives, shape design optimization and nonlinear control of electrical machines. 